various planetary systems with the 26 .inch refractor of the United States Naval Observatory at Washington. In the Astronomische Nachrichten (Bd. I 54, Nos. 3686-7) he gives the details and results of the investigations of Saturn, including measures of the planet, rings, and the satellite Titan, He attributes much of the consistency of the values determined to the use of various colour screens placed between the eye and the telescope, which reduces or eliminates entirely the secondary spectrum produced by the objective, thereby enabling a much more sharply defined disc to be obtained.

In addition to his own recent measures, the author also brings together previous work on the subject from 1659 . The following is a summary of the new determinations :-

External diameter of the outer ring $\ldots=40^{\prime \prime} \cdot 304$ Internal diameter of the outer ring, or $\}=34787$ Diameter of the centre of Encke's division $=37.777$ Width of Encke's division $\ldots . \quad \ldots=0.107$ Total width of the outer ring $\ldots \quad \ldots=2.75^{8}$ Width of the outer part of the outer ring $=1.237$ Width of the inner part of the outer ring $=\mathrm{I} \cdot 4 \mathrm{I} 4$ External diameter of central ring $\ldots=33.95 \mathrm{I}$ Internal diameter of central ring, or $=25.952$ $\begin{array}{ll}\text { External diameter of dusky ring } \quad \ldots i & =2595^{2} \\ \text { Width of central ring ... } \ldots . . . & =4.000\end{array}$

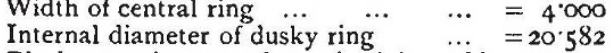
Black space between Saturn's globe and $\}=r \cdot 567$ $\begin{array}{lllll}\text { dusky ring } & \ldots & \ldots & \ldots & \ldots\end{array}$ Equatorial diameter of Saturn $\ldots . . . . .6=17.448$ Assumed oblateness of Saturn (H. Struve) Polar diameter with this oblateness Assumed mass of Saturn (Bessel) Resulting mean density of planet $=15.68 \mathrm{I}$ $0 \cdot 1013$ $=1: 3501 \cdot 6$

$=0.1234=0.679$ that of water.

Diameter of the satellite Titan $=0.487$

$\mathrm{km}$.
278,768 240,610 261,290

179,501

27,667

142,359

10,838 I 20,682 108,457 79 Width of Cassini's division $\ldots . \quad \ldots=0.418$ 3,368

\section{HYDROGEN IN AIR}

IN a recent number of the Annales de Chimie ei de Physique (January, IQOI), M. Armand (*autier, professor of chemistry at the Ecole de Mćdicine, Paris, gives a connected account of his researches on the combustible gases of the atmosphere. These researches have occupied some years, they have been carried out with extraordinary care and completeness, and they have yielded results of very great interest both in regard to their main object and also in relation to incidental scientific questions.

The most striking fact elicited by M. Gautier is that pure air contains free hydrogen as a normal constituent to the extent of about two volumes in 10,000 . This conclusion, taken in conjunction with the recent experiments of Profs. Liveing and Dewar (NATURE, December 20, 1900, p. 189), in which they record the isolation of a fraction of air containing 43 per cent. of hydrogen, which they actually exploded, seems to admit of no doubt.

Analytical Methods. - M. Gautier set himself to determine the character and amount of combustible gases in the atmosphere by aspirating a large volume of air through a train of absorbents. Nothing could be more obvious and simple in principle than such a method; the difficulty of making it available for determining with any legree of certainty the character and quantity of very small amounts of combustible gases will, however, be thoroughly appreciated by chemists.

The first part of M. Gautier's memoir is devoted to a descrip. tion of the preliminary work which was necessary for the selection and proper use of the absorbents. Beginning with carbon dioxide, he confirmed the previous observation of Boussingault and Eliot and Storer that carbon dioxide is very difficult to absorb from a large admixture of other gases. After circulating 90 litres of ordinary air during forty-eight hours through a tube 80 centimetres long and containing glass beads moistened with caustic potash solution of density 13 , it was found that 10.7 c.c. per million of $\mathrm{CO}_{2}$ remained unabsorbed. A satisfactory absorbent in respect both to rapidity and complete. ness was found in barium hydrate, either dissolved or simply moistened with water. This substance would, of course, also absorb other acid gases, such as $\mathrm{H}_{2} \mathrm{~S}, \mathrm{SO}_{2}$ and $\mathrm{NO}_{2}$.

$$
\text { No. I6 } 37 \text {, VOL. } 63 \text { ] }
$$

The desiccation of air by sulphuric acid was also shown to be incomplete; a satisfactory agent was found in phosphoric oxide previously heated with oxygen at $260^{\circ} \mathrm{C}$. to get rid of lower oxides.

For the absorption of minute quantities of carbon monoxide the ordinary reagents are ineffective and a new one was found in iodine pentoxide. Air containing $1 / 100,000$ th of the gas loses it completely and at once when passed over the pentoxide heated to $70^{\circ} \mathrm{C}$. Carbon dioxide, oxygen, nitrogen, hydrogen, marsh gas have no action on the oxide at that temperature, and other more strongly reducing gases, such as alcohol vapour and benzene when much diluted are also without action. When carbon monoxide acts upon iodine pentoxide, iodine and carbon dioxide are produced; the iodine is absorbed by a tube containing finely divided copper and the carbon dioxide by barium hydrate. The estimation of hydrogen and hydrocarbons is next dealt with. When a mixture of 50 c.c. of hydrogen with 235 litres of pure air was passed over heated oxide of copper the hydrogen was entirely burnt provided that a tube of 70 centimetres was emplnyed. With a tube of 30 centinetres, only 70 per cent. of the hydrogen was burnt. When using shorter tubes in subsequent experiments the weight of water olstained had to be multiplied by a factor in order to give the effect of an "infinite" tube of copper oxide.

When diluted marsh gas is passed over heated copper oxide there is neither complete combustion nor equivalent combustion of the carbon and hydrogen, and here also the use of factors is necessary. The hydrogen burns in greater proportion than the carbon. With a diluted mixture of marsh gas and hydrogen it was found that the presence of the hydrogen facilitated the combustion of the hydrogen of the marsh gas but retarded that of the carbon. Admixture of the copper oxide with spongy platinum or with other metallic oxides did not improve the efficiency. It was found that the copper oxide, after continued heating to redness, gradually lost its power of oxidising, and after 1500 hours it was without effect upon hydrocarbons, and it only partially oxidised free hydrogen.

For a detailed description and drawing of the apparatus the original memoir must be consulted. The air was filtered from suspended impurities by filtration through glass wool, its carbon dioxide was then absurbed-and in this connection the author devised a special form of absorption tube which he strongly recommends-ivater was then absorbed and the air entered the combustion tube. The combustion tube was heated in a furnace of special construction, in which great uniformity of temperature cculd be maintained from end to end. Water and carbon dioxide formed by combustion were then absorbed, and the apparatus terminated in an aspirator, a "decanteur" and a meter. There were in all twenty-eight pieces in the train; they were connected together by clamped india-rubber joints made from purified tubing, which experiment showed to be proof against diffusion.

The Air of Paris.-Beginning first with towns, M. Gautier examined the air in the region of the licole de Médicine. The average ratio of carbon and hydrogen found corresponded pretly nearly to $\mathrm{CH}_{4}$, but there was evidence at times of some more highly carburetted hydrocarbon being present, at others of free hydrogen.

There was no evidence of hydrocarbons of the ethylene or acetylene series being present.

The quantity of carbon monoxide found was extremely small, it averaged $2 \cdot 1$ I volumes per million, but this included one very abnormally high instance. Neglecting this one instance the average of $\cdot 56$ volume per million was obtained. The quantity of carbon monoxide varied in different places; it increased in densely populated places. In a small roon at the laboratory heated by an old-fashioned faïence stove and illuminated for several hours by three gas jets $12 \cdot 3$ volumes were found. On the whole the quantity of $\mathrm{CO}$ and unsalurated hydrocarbons in town air may be said to be insignificant.

The Air of Fores/s. - The next experiments related to the air of forests, and the station fixed upon was a clearance in the middle of a wood at Lainville, 70 kilometres from Paris.

Here the proportion of carbon to hydrogen printed distinctly to the presence of free hydrogen along with marsh gas. It did not seem probable that the hydrogen came directly from living vegetation, but it was possible that it might arise from decom. position going on in the soil, and it was therefore decided to make analyses in localities where this possible source would be removed to a large extent. 
Mountain Air.-With the object just referred to, the next station selected was in the Pyrenees on the Pic Canigou, a barsen mountain 2785 metres in height. The transport of the apparatus to this remote station required six porters and mules, and M. Gautier with his presparateur and one guide were left to make the best of a rock cabin amidst the snow, fires being suppressed in order to avoid contamination of the atmosphere.

Under these cheerless conditions a series of determinations was made which amply realised the anticipation that in the absence of vegetation and soil the proportion of marsh gas would diminish. The quanticy found was 2.19 volumes per 100,000 as against II 3 for the air of woods and $22 \cdot 6$ for the air of Paris.

The quantity of free hydrogen reached 17 parts per 100,000 .

Sea Air. - M. Gautier now decided to get rid of vegetation altogether by going out to sea, and took up his station during the autumn equinox at the iron lighthouse of the RochesDouvres, 40 kilometres from the coast of Brittany. He arrived after a series of north-west gales, and was, he says, altogether tris favorise par les circonstances. Analysis showed a fall in the proportion of carbon to $1 / 33$ of what it was in mountain air, that is, to an almost negligible quantity. There was an increase in the amount of free hydrogen to $19^{\circ} 5$ vols. per 100,000 . It appears, therefore, that the air over the sea and at very high altitudes is nearly free from hydrucarbons, and that it contains two vols. in 10,000 of free hydrogen, a proportion, it will be observed, about two-thirds of that of the atmospheric carbonic acid.

Source of the Gases. - In the concluding section of his memoir, $\dot{M}$. Gautier discusses in more detail the nature of the accessory combustible gases in the air and the origin of atmospheric hydrogen. He concludes that, subject to variations, the com. bustible gases of Paris air may be set down as follows, in volumes per 100,000:-Free hydrogen 19.4, methane 12. I, benzene vapour or analogous compounds $I^{\prime} 7$, carbon monoxide and traces of olefines and acetylenes $\cdot 2$.

It remains now only to show that the presence of hydrocarbons in air is in accordance with established geological facts, and that it is connected with the occurrence of the larger quantities of free hydrogen. M. Gautier points out that methane is exhaled from many soils, that it is the chief constituent of firedamp, that it occurs with petroleum and is emitted by volcanoes, especially by mid volcanoes. Hydrogen often accompanies methane in these cases, and has been found in the fumerolles of Iceland and Tuscany. These outbursts are only extreme manifestations of actions which have been silently in continual progress for ages. The occurrence of hydrogen occluded in rocks has been pointed out by Fouqué and by Tilden. M. Gautier has himself greatly extended earlier researches. He finds that many specimens of granite treated with water at $280^{\circ} \mathrm{C}$. or with dilute acids at $100^{\circ}$, yield a considerable volume of gas. Thus, in one case, a kilogramme of granite heated with diluted phosphoric acid gave the following volumes in c.c. : $-\mathrm{H}_{2} \mathrm{~S} \mathrm{I}^{\prime} 2, \mathrm{CO}_{2} 27^{\circ} \cdot 6, \mathrm{C}_{2} \mathrm{H}_{2}{ }_{12} \cdot 3, \mathrm{CH}_{4}$ trace, $\mathrm{N}_{2}$ (rich in argon) $230^{\circ}, \mathrm{H}_{2} 53$.

It seems protable that when the igneous rocks were solidifying and their components crystallising, they included small quantities of the primitive earth materials which now form the subjacent zone, that is to say, sulphides, nitrides, argonides, heliides, hydrocarbons, carbides, fluorides, iodides, phosphides, arsenides, \&c. These substances, by the action of water, aided or not by acids, gave rise to the observed gases. As to the hydrogen, M. Gautier is assured by experiments, which he does not now detail, that it comes from $(a)$ the action of water at a red heat on ferrous compounds, (b) the destruction by heat of hydrocarbons formed previously by the action of water on metallic carbides, $(c)$ in a less degree by the action of water at a red heat on certain nitrides.

Hydrocarbons come from the action of water on small quantities of metallic carbides, especially those of aluminium and iron, included in the rocks.

Many more details of geological and chemical interest are given by M. Gautier. He insists that it is not necessary to imagine that water penetrates to the molten material lying below the solid crust of the earth. It is sufficient for the water to reach the low layers of rock containing these small quantities of included raw materials. On the other hand, it is not to be supposed that the gaseous products of the action of water on the raw materials will all escape from the surface. Some of the gases will combine with the rocks, and some on reaching the region of oxygen will be oxidised; but others, including methane, the petroleum hydrocarbons, nitrogen and hydrogen, not readily oxidised except at high temperatures, will escape into the air.

M. Gautier deals briefly with the question as to whether the hydrogen will tend to accumulate in the upper regions of the atmosphere. Without committing himself to a definite opinion, he quoles the views of Dr. Johnstone Stoney as to the impossibility of the earth's gravitational attraction being sufficient to retain helium or hydrogen. If the view is accepted that some of the hydrogen molecules at the fringe of the atmosphere have a velocity outwards of II, 000 metres per second, their escape would be possible, and we should have to picture a continual flux of hydrogen from the earth's surface through the atmosphere into interstellar space.

It is interesting to note that Profs. Liveing and Dewar incline perhaps to a different view. They say "if the earth cannot retain hydrogen or originate it, then there must be a continued accession of hydrogen to the atmosphere (from interplanetary space), and we can hardly resist the conclusion that a similar transfer of other gases must also take place."

Whatever view be correct as to the source and retention of atmospheric hydrogen, there can be no longer any doubt not only of its presence but of its abundance, and the establishment of this fact marks an advance in knowledge highly important from many points of view.

A. S.

\section{SCIENTIFIC AGRICULTURE IN THE UNITED} $S T A T E S .^{1}$

A GRICULTURAL experiment stations are now in operation under the act of Congress of March 2, 1887, in all the States and Territories of the United States. Agricultural experiments have been begun in Alaska with the aid of national funds, and an experiment station is in operation in Hawaii under private auspices. In each of the States of Alabama, Connecticut, New Jersey and New York a separate station is maintained wholly or in part by State funds, and in Louisiana a station for sugar experiments is maintained partly by funds contributed by sugar planters. Excluding the branch stations established in the several States, the total number of stations in the United States is 54 . Of these 52 received the appropriation provided for in the act of Congress above mentioned. The total income of the stations is about 1, 143,334 dollars, of which 720,000 dollars was received from the National Government, the remainder, $423,334.93$ dollars, coming from the following sources: State Governments, 240,300.20 dollars; individuals and communities, I 2, 100 dollars ; fees for analyses of fertilisers, 75, 294.42 dollars; sales of farm products, 69, 312.60 dollars; miscellaneous, $26,327.7$ I dollars. In addition to this the Office of Experiment Stations has an appropriation of 40,000 dollars for the past fiscal year, including 10,000 dollars for the Alaskan investigation.

The stations employ 678 persons in the work of administration and inquiry. The number of officers engaged in the different lines of work is as follows:-I)irectors, 71 ; chemists, 148; agriculturists, 68 ; experts in animal husbandry, 9 ; horticulturists, 77; farm foremen, 21 ; dairymen, 23; botanists, 52 ; entomologists, 48 ; veterinarians, 26 ; meteorologists. 17 ; biologists, 7; physicists, 7; geologists, 5; mycologists and bacteriologists, 20 ; irrigation engineers, 5 ; in charge of substations, 16; secretaries and treasurers, 24; librarians, 9 ; and clerks, 43. There are also 48 persons classified under the head of "miscellaneous," including superintendents of gardens, grounds and buildings, apiarists, herdsmen, \&c. Three hundred and eight station officers do more or less teaching in the colleges with which the stations are connected.

During 1899 the stations published 445 annual reports and bulletins, containing 16,924 pages. Besides regular reports and bulletins, a number of the stations issued Press bulletins, which were widely reproduced in the agricultural and county papers. In a recent report on the work and expenditures of the stations, Mr. A. C. True, the Director of the Experiment Station Office, makes the following general statements :-

The work of the stations during the past year has for the most part been along the same lines as heretofore, and in the 1 Abridged from the Experiment Station Record (vol, xi. No. 9), pub ished by the U. S. Department of Agriculture. 